\title{
Driving and diabetes: are the changes in the European Union licensing regulations fit for purpose?
}

\author{
ALEX J GRAVELING, ${ }^{1}$ BRIAN M FRIER²
}

\begin{abstract}
Driving is an important everyday activity for many people with diabetes, which is designated a prospective disability as it may impair driving performance as it progresses in severity. In effect, the principal threat to driving performance is hypoglycaemia associated with insulin therapy. Regular assessment of medical fitness to drive is undertaken to identify drivers with diabetes who are at greatest risk of experiencing motor vehicle accidents. Many countries do not restrict the licensing of drivers with insulin-treated diabetes and fail to review and/or restrict the driving of large goods vehicles or those carrying passengers. The European Union has formulated regulations for driving licensing for diabetes through successive directives, which have been implemented by individual countries including the UK. In response to submissions to relax licensing restrictions, some of these have been amended recently and were implemented in the UK in January 2018. Their rationale and potential value are discussed.
\end{abstract}

Br J Diabetes 2018;18:25-31

Key words: driving, driving licensing, road traffic accidents, hypoglycaemia, type 1 diabetes, insulin therapy

\section{Introduction}

Driving is an everyday activity that is essential for many occupations and to facilitate transportation; as such, it is of substantial economic and personal importance. As driving is a complex activity that involves several cognitive domains and imposes metabolic demands, effective driving performance demands that cognitive function must be intact. Adequate vision is also a prerequisite. While motor vehicle accidents may have multiple contributing factors (eg, adverse road conditions and vehicular failure), several

J J R Macleod Centre for Diabetes \& Endocrinology, Aberdeen Royal Infirmary, Foresterhill, Aberdeen, UK

The Queen's Medical Research Institute, The University of Edinburgh, Edinburgh, UK

Address for correspondence: Professor Brian M Frier The Queen's Medical Research Institute, The University of Edinburgh, Edinburgh EH16 4TJ, UK

E-mail: brian.frier@ed.ac.uk

https://doi.org/10.15277/bjd.2018.170 medical disorders can affect fitness to drive and may increase the risk of accidents. Drivers with these conditions are therefore subject to licensing restrictions enforced by statutory regulation. Diabetes is designated as a prospective disability for driving because of various potential problems that may progress with time; to retain their driving licences, drivers with insulin-treated diabetes are required to undergo regular assessment of their medical fitness to drive.

Why is diabetes potentially dangerous for drivers? Complications of diabetes such as retinopathy and peripheral neuropathy can impair driving performance and increase the risk of a road traffic accident (RTA). ${ }^{1}$ However, the risk of developing hypoglycaemia is the pre-eminent concern when assessing fitness to drive. This risk is greatest in people treated with medications that carry a substantial risk of hypoglycaemia - namely, the sulfonylureas, glinides and insulin - and increases with duration of treatment with insulin. One survey of drivers with insulin-treated diabetes suggested that $13 \%$ had experienced hypoglycaemia while driving during the preceding year. ${ }^{2}$

\section{Do patients with diabetes experience more road traffic accidents?}

Analysis of various studies has suggested that an increased risk of RTAs does exist, but is very modest. ${ }^{3} \mathrm{~A}$ more recent meta-analysis has concluded that the overall risk of RTAs for drivers with diabetes was not higher than for non-diabetic drivers; older drivers and those with insulin-treated diabetes exhibited a trend towards an increased risk, but this failed to reach statistical significance. ${ }^{4}$ However, proving causation remains extremely difficult as the cause of many accidents is multifactorial and factors such as the age and gender of the driver, type of road, traffic conditions and time of day all influence the baseline risk of sustaining a RTA. In addition, drivers at high risk may voluntarily cease driving or have their licences revoked and, as a result, no longer contribute to RTA statistics.

Can we identify drivers with diabetes at risk of road traffic accidents?

Identification of drivers with diabetes most likely to be involved in a RTA would allow interventions to be targeted at those at higher risk. To assist this task, Cox and colleagues have developed an 11item questionnaire to identify high-risk drivers and have shown that an online intervention reduced the incidence of driving mishaps over a 12-month period. ${ }^{5}$ 


\section{How are people with diabetes licensed to drive motor vehicles in different parts of the world?}

Because of the potential problems with driving performance, many professional bodies and licensing authorities provide advice and guidance for drivers with insulin-treated diabetes. ${ }^{6-8}$ In their licensing regulations, European countries differentiate between people driving cars and motor cycles (Group 1 vehicles) and those driving larger vehicles such as buses or large lorries and trucks (Group 2 vehicles). Group 2 licensing regulations are much stricter in view of the increased potential for causing significant injury or loss of life.

Despite the potential issues that a driver with diabetes may face, most countries in the less developed parts of the world, but also many affluent countries in the Middle East, currently fail to place any restriction on driving for people with insulin-treated diabetes. A recent global survey of 85 countries revealed wide variation in practice and, surprisingly, many national diabetes organisations declined to provide information about the legislation (which is mostly non-existent) on the position regarding regulations for driving licensing in their countries. ${ }^{9}$ Of the countries in South-East Asia who responded to this survey, none currently impose any form of licensing restriction on drivers with diabetes, unlike most countries in Europe, North America and Australasia. It was particularly disconcerting to find that, in two-thirds of those countries, no restriction is placed on the driving of large goods vehicles (Group 2 classification in Europe) by people with insulin-treated diabetes, and a 'call to arms' from concerned diabetes specialists in some of the countries with either no or less stringent regulation has been ignored. ${ }^{10}$ Political inertia, combined with reluctance to commit resources to regulating medical disorders that can affect fitness to drive, are widespread problems on a global scale, and presumably contribute to the high fatality rates that are associated with driving in many parts of the world. ${ }^{11}$

\section{How are people with diabetes licensed to drive motor vehicles in the European Union?}

Over a period of years, the European Union has issued directives on driving with agreed policies for licensing regulations; adoption by member states is mandatory. However, the licensing recommendations for drivers with diabetes in the 2 nd Directive (91/434/EEC) in 1991 were not being applied uniformly by member states and, in some countries, were effectively being ignored - particularly in relation to the issue of Group 2 licences. This allowed professional drivers with insulin-treated diabetes, who had been subject to widely varying standards for the issue of Group 2 licences, to cross national borders when driving large lorries and coaches. This anomaly was considered politically unacceptable by the British Government.

The 3rd Directive on Driving in 2006 (Annex III to European Directives 91/439/EEC and 2006/126/EC) therefore sought to update and unify the regulatory practices of EU states to licensing drivers with respect to insulin-treated diabetes, and the changes imposed by this Directive were implemented in the UK in September 2010. The new Directive specified that the interval between regular medical review for a Group 1 licence should not exceed 5 years, which required no change of practice in the UK where review was already being undertaken every 3 years. If a driver experienced more than one episode of severe hypoglycaemia (at any time of day or night) in the preceding 12 months, revocation of the licence would be necessary and could not be renewed until the frequency of severe events had returned to a total of one single event within the preceding year. Several months could therefore elapse before application to restore the driving licence could be made. A driver must not have impaired awareness of hypoglycaemia, although this condition was not defined in the EU Directive and interpretation of how this syndrome should be identified was left to the discretion of individual states. Previously, drivers with insulin-treated diabetes had been debarred from applying for Group 2 licences, which was strictly enforced in the UK, but from November 2011 this was reversed to allow application providing various strict standards could be met, including no history of severe hypoglycaemia and full awareness of hypoglycaemia, and regular blood glucose monitoring (at least twice daily at times relevant to driving) must be performed. In the UK, a glucose meter with a memory facility had to be used to ensure not only that blood glucose tests had been performed at the requisite times, but also to provide an accurate record of the results that was not susceptible to manipulation.

It is not surprising that some of these changes were controversial and potentially self-defeating. It was thought that the need to self-report more than one episode of severe hypoglycaemia in any 12-month period, the consequence being the immediate suspension of an individual's driving licence for up to 12 months, might discourage a driver from reporting episodes of severe hypoglycaemia because of fear of losing their driving licence. Apart from the social inconvenience of being unable to drive, a person's employment could be jeopardised. This concern was fully justified. A Danish study demonstrated that the rates of severe hypoglycaemia reported by adults with type 1 diabetes declined by $55 \%$ in the year following implementation of these new EU regulations in Denmark. ${ }^{12}$ A further study in Denmark reported that $23 \%$ of drivers with diabetes holding a Group 1 licence and $16 \%$ of those holding a Group 2 licence would consider under-reporting their episodes of severe hypoglycaemia. ${ }^{13}$ Two or more episodes of severe hypoglycaemia in the last 12 months were reported by $10.4 \%$ of participants with a current driving licence, suggesting that underreporting of severe hypoglycaemia was indeed commonplace. In a survey of attitudes to the EU regulations in drivers with insulintreated diabetes in the Czech Republic, many averred that they would conceal exposure to recent severe hypoglycaemia because they feared losing their driving licence. ${ }^{14}$ Concealment of material facts in relation to application for, or renewal of, Group 1 driving licences is not a new phenomenon. A review of applications to the Driver and Vehicle Licensing Agency (DVLA) in the UK for renewal of Group 1 licences by drivers with type 1 diabetes of more than 15 years' duration showed that one in 10 were providing inaccurate or frankly misleading information that differed considerably from that provided in medical reports from their doctors..$^{15}$

The standards of fitness to drive for people with diabetes were last updated by EU Directive in 2009. This update was transposed into UK law through the Motor Vehicles (Driving Licences) (Amendment) regulations in 2011. Following the change in regulations in 
2010/2011, several member states, including the UK, approached the European Commission to express the view that they considered the current provisions for Group 1 drivers to be too strict, and specifically that severe hypoglycaemic episodes occurring during sleep should not carry the same weight in the assessment of fitness to drive as those occurring during waking hours. In response to this lobbying, the European Commission adopted changes recommended by their Diabetes Working Group and issued Directive 2016/1106/EC, which has amended the earlier 3rd Directive on Driving (2006/126/EC).

\section{How have the EU driving regulations changed in the UK from January 2018?}

The latest EU directive, which was published in 2016, required the proposed changes to be implemented by January 2018. ${ }^{16}$ They refer to drivers holding Group 1 licences alone. The regulations for Group 2 licences are unchanged. The key changes (our italics denote important amendments) are summarised in table 1 :

- Driving licences shall not be issued to, or renewed for, applicants or drivers who have inadequate awareness of hypoglycaemia.

- Driving licences shall not be issued to, or renewed for, applicants or drivers who have recurrent severe hypoglycaemia, unless supported by competent medical opinion and regular medical assessment. For recurrent severe hypoglycaemias during waking hours a licence shall not be issued or renewed until 3 months after the most recent episode.

- Driving licences may be issued or renewed in exceptional cases, provided that it is duly justified by competent medical opinion and subject to regular medical assessment, ensuring that the person is still capable of driving the vehicle safely taking into account the effects of the medical condition.

\section{Inadequate awareness of hypoglycaemia}

This is simply a minor change in semantics, replacing the term 'impaired' with 'inadequate' when describing an altered state of awareness of hypoglycaemia. It appears to have been made in response to the argument that the state of awareness of hypoglycaemia can vary over time, and that diminished awareness may be reversible. If anything, this altered terminology is even more vague than before and still fails to define precisely what this clinical problem represents, its nature and severity, and how it should be assessed and applied in relation to fitness to drive. Several validated methods of assessing awareness of hypoglycaemia are available and have been compared favourably to show good concordance. ${ }^{17}$ The revised EU regulations have therefore missed an opportunity to try to standardise the definition and assessment of impaired awareness of hypoglycaemia. Instead, a non-standard term has been adopted that can be interpreted differently by individual member states and their licensing authorities, risking variable implementation across Europe.

Because total loss of symptoms of hypoglycaemia is uncommon, in the UK this has been used as the definition relevant to driving Group 1 vehicles, otherwise many drivers with insulin-treated diabetes would have been debarred without any firm evidence that they had a higher rate of driving mishaps. Interestingly, although significant impairment of awareness of hypoglycaemia potentially can pose a risk to safe driving and has been described anecdotally as a cause of motor vehicle accidents, in several large studies it has not emerged as a relevant factor causing driving mishaps. ${ }^{18}$ This suggests that driving accidents associated with this clinical problem are relatively uncommon. This may be a consequence of more frequent blood glucose monitoring by drivers who have some degree of impaired awareness, ${ }^{2}$ or their voluntary cessation of driving when loss of awareness becomes severe.

Table 1 Changes to DVLA regulations for drivers with insulin-treated diabetes

\begin{tabular}{|c|c|}
\hline $\begin{array}{l}\text { Licence type and } \\
\text { time period }\end{array}$ & $\begin{array}{l}\text { Group } 1 \text { (Car and motorcycle) } \\
\text { Since } 2006\end{array}$ \\
\hline $\begin{array}{l}\text { Drivers with insulin-treated } \\
\text { diabetes }\end{array}$ & $\begin{array}{l}\text { Must meet the criteria to drive and must notify the } \\
\text { DVLA. All the following criteria must be met for the } \\
\text { DVLA to issue a 1-, 2- or 3-year licence }\end{array}$ \\
\hline Awareness of hypoglycaemia & Adequate awareness of hypoglycaemia \\
\hline Hypoglycaemic episodes & $\begin{array}{l}\text { No more than one episode of severe } \\
\text { hypoglycaemia in the preceding } 12 \text { months }\end{array}$ \\
\hline $\begin{array}{l}\text { Blood glucose monitoring } \\
\text { recommendations }\end{array}$ & $\begin{array}{l}\text { Practises appropriate blood glucose monitoring (blood } \\
\text { glucose testing no more than } 2 \text { hours before the start } \\
\text { of the first journey and every } 2 \text { hours while driving) }\end{array}$ \\
\hline Miscellaneous & $\begin{array}{l}\text { Applicant must not be regarded as a likely risk to the } \\
\text { public while driving }\end{array}$ \\
\hline
\end{tabular}

Eye sight complications
Meets the visual standards for acuity and visual field

\section{Group 1 (Car and motorcycle) Since 2018}

Unchanged

Driving licences shall not be issued to, or renewed for, applicants or drivers who have inadequate awareness of hypoglycaemia

For recurrent severe hypoglycaemia during waking hours a licence shall not be issued or renewed until 3 months after the most recent episode

Unchanged

Unchanged, driving licences may be issued or renewed in exceptional cases, provided that it is duly justified by competent medical opinion and subject to regular medical assessment, ensuring that the person is still capable of driving the vehicle, safely taking into account the effects of the medical condition

Unchanged 


\section{Reduction in length of time of revocation of a driving licence from 12 to 3 months}

The most powerful factor for predicting the risk of severe hypoglycaemia is a history of severe hypoglycaemia, as was shown in the 30-year analysis of the DCCT/EDIC data. ${ }^{19}$ Furthermore, previous exposure to severe hypoglycaemia was the factor most consistently identified with an increased risk of RTAs in people with diabetes; a history of severe hypoglycaemia in the preceding two years was associated with a four-fold higher risk of accidents. ${ }^{20,21}$ Thus, the original criterion of limiting the number of episodes of severe hypoglycaemia to no more than one in a single calendar year was evidence-based and was not chosen arbitrarily. The problem remains how to identify and record episodes of severe hypoglycaemia and how to implement this otherwise reasonable criterion when this relies on self-reporting of episodic severe hypoglycaemia by drivers treated with insulin. Most severe episodes are treated at home or in the community by family, friends or work colleagues; only $10 \%$ of events in people with type 1 diabetes and $30 \%$ in insulin-treated diabetes involve emergency medical services and are likely to be documented in medical records. ${ }^{22}$ Drivers with diabetes soon realised that reporting their experience of severe hypoglycaemia to their medical attendants would lead to revocation of their driving licences, so their honesty was being penalised. This presumably explains the dramatic reduction in the self-reported frequency of severe hypoglycaemia in Denmark, which was much lower than rates obtained by anonymous reporting. ${ }^{12}$

Concealment of any material fact relevant to fitness to drive when applying for a driving licence is breaking the law but, in reality, the DVLA has rarely prosecuted any driver on these grounds. However, should a claim be made following a driving accident, motor insurance companies would most definitely repudiate insurance cover in this situation, so deliberate concealment of previous episodes of severe hypoglycaemia could incur a heavy personal cost, notwithstanding the increased risk to public safety. The latter was demonstrated by the fatalities resulting from the tragic bin lorry accident in Glasgow in December 2015, where it emerged that the driver (who did not have diabetes) had deliberately concealed recurrent blackouts from his medical attendants and also the DVLA. Collusion with a driver with diabetes to conceal a history of severe hypoglycaemia when providing a medical report for renewal of a driving licence could also compromise the integrity of the patient's medical attendant. The General Medical Council has recently released guidance specifically discussing concerns over a patient's fitness to drive and when to report this to the DVLA. ${ }^{23}$

Understandably, the reduction in time between possible renewal of a driving licence to 3 months after the most recent episode of severe hypoglycaemia has been hailed as a victory for common sense and natural justice by diabetes charities, who represent the interests of their members. However, what the revised regulations do not explain is what should be put in place in terms of corrective treatment following the second severe episode of hypoglycaemia and how long should be allowed for this to be dealt with effectively. Presumably the driver whose licence has been revoked on these grounds must satisfy the regulatory authority (i.e. the DVLA in the UK) that significant steps have been taken to reduce the likelihood of any further episode of severe hypoglycaemia before they can be sanctioned to resume driving. This will inevitably require specialist diabetes input and effective changes in management are unlikely to be implemented and reviewed to the satisfaction of healthcare professionals within 3 months.

Restricting relevant severe hypoglycaemia to waking hours The EU regulations in the 3rd Directive did not differentiate between whether severe hypoglycaemia was occurring while the driver was awake or asleep. Although sleep mostly occurs at night, it can take place at any time of day. In the DCCT, $55 \%$ of severe events occurred during sleep compared with $43 \%$ during the night. ${ }^{24}$ However, in everyday life, hypoglycaemia of any severity that occurs during sleep is often difficult to detect without the use of continuous glucose monitoring (CGM), which has demonstrated that low glucose levels can persist for several hours during sleep. People are not aware of hypoglycaemia during sleep and seldom awaken, so the frequency of nocturnal hypoglycaemia is generally underestimated. ${ }^{25}$ It is often difficult to know if an individual has experienced a severe event during sleep as judged by the development of profound neuroglycopenia, as they usually recover spontaneously with time. It is only when hypoglycaemia during sleep induces a seizure or the person is found to be comatose and unrousable that an episode is recognised to be severe in nature. Severe hypoglycaemia in patients who sleep alone is less likely to be detected than those who are wakened by partners noticing features suggestive of hypoglycaemia. Consequently, those severe events that have occurred during the night or during sleep at other times of day and have been identified and reported to driving authorities are likely to be relatively few in number. The exclusion of severe hypoglycaemia events during sleep may not make much difference to licensing as many of these events are not being detected in the first place.

It is argued that, as a person is not driving while asleep, severe hypoglycaemia at this time has no relevance to medical fitness to drive and should therefore be discounted with respect to documentation of the number of severe events in a year, which should then be restricted to events occurring solely during waking hours. This premise has been accepted by the EU Commission and is reflected by this change in regulations. However, disregarding sleep-associated severe hypoglycaemia takes no account of the after-effects on the individual following recovery of blood glucose. This change may therefore be contentious as it may not promote safe driving.

Hypoglycaemia during sleep in adults with type 1 diabetes has been shown to have variable effects on cognitive function the following morning, but all experimental and observational studies have recorded adverse effects on mood and well-being. ${ }^{26-28}$ Affected individuals felt tired, slow, depressed and restless on the day after nocturnal hypoglycaemia. ${ }^{29-31}$ Negative effects have been reported on work attendance, performance and productivity. ${ }^{28-31}$ There is evidence that hypoglycaemia during sleep is relevant to a person's ability to function normally after awakening, whether this is in the morning after nocturnal hypoglycaemia or at some other time of day. Following an episode of severe nocturnal hypoglycaemia, drivers should be advised to avoid driving the following 
day, at least in the hours after awakening. The ability to drive a vehicle safely following sleep-related hypoglycaemia has not been studied and lacks evidence, so this suggestion would be difficult to mandate. This change in the EU regulations has been welcomed by many as a common sense measure and a further important step in reducing the burden of current restrictions on drivers with diabetes. Whether this is a sensible change as far as public safety is concerned remains to be seen. The reduction in the importance of sleep-related severe hypoglycaemia with respect to fitness to drive has not been extended to include drivers holding Group 2 licences, in whom any episode of severe hypoglycaemia will lead to revocation of the vocational licence.

\section{Exceptional cases}

An individualised approach is now recommended in many areas of healthcare, and driving is no exception. At the very least it allows those who perceive themselves as having been treated unfairly by the system to have some right of appeal. Competent medical opinion has not been defined and will be left to the discretion of individual member states.

\section{Are drivers with diabetes aware of the regulations surrounding diabetes and driving?}

Awareness of driving regulations among people with diabetes remains limited. A UK-based study showed that $60 \%$ either never test blood glucose before driving or only if symptomatic of hypoglycaemia. A more recent study of people in the UK with type 2 diabetes treated with sulfonylurea or insulin therapy suggested some improvement, with $18 \%$ and $6 \%$ reporting never testing before driving although only $22 \%$ tested before every journey. 2,32

\section{Are healthcare professionals aware of the regulations regarding diabetes and driving?}

Knowledge of driving regulations is deficient among many healthcare professionals (HCPs) involved in diabetes care. A study in Wales showed that a third of HCPs were unaware of the recommended minimum blood glucose level for driving $(5.0 \mathrm{mmo} / \mathrm{L})$. Around half though that a car driver who had developed impaired awareness of hypoglycaemia should be advised to stop driving at least temporarily until hypoglycaemia awareness has been restored. On a more positive note, $92 \%$ knew that a person with newly diagnosed type 1 diabetes can continue driving but is required to report their medical condition to the DVLA. ${ }^{33}$ A previous Scottish study had revealed similar deficits in knowledge, ${ }^{34}$ so little appears to have changed regarding the comprehension of HCPs about driving and diabetes and how licensing is regulated.

\section{Blood glucose retest interval recommended by the DVLA}

The blood glucose testing interval in relation to driving is not proscribed by EU directive but is a recommendation for safe driving issued by the DVLA. These recommendations prompt drivers with insulin-treated diabetes to check their capillary blood glucose up to 2 hours before commencing driving and then at 2-hourly intervals. A driver could therefore leave up to 4 hours between tests yet
Table 2 Percentage of participants experiencing hypoglycaemia (blood glucose $<3.9 \mathrm{mmol} / \mathrm{L}$ ) at certain time periods after blood glucose $>5.0 \mathrm{mmol} / \mathrm{L}^{35}$

\begin{tabular}{|llll|}
\hline & $\begin{array}{l}\mathbf{1 . 5} \text { hours } \\
\text { after }\end{array}$ & $\begin{array}{l}\mathbf{2} \text { hours } \\
\text { after }\end{array}$ & $\begin{array}{l}\mathbf{4} \text { hours } \\
\text { after }\end{array}$ \\
\hline Type 1 diabetes & $10.0 \%$ & $13.8 \%$ & $22 \%$ \\
\hline $\begin{array}{l}\text { Type 2 diabetes } \\
\text { (insulin-treated) }\end{array}$ & $3.1 \%$ & $4.4 \%$ & $8.4 \%$ \\
\hline
\end{tabular}

remain compliant with these recommendations. Flash CGM was utilised in a blinded manner to demonstrate how hypoglycaemia can develop in people after they had demonstrated a satisfactory capillary blood glucose $(>5 \mathrm{mmol} / \mathrm{L}$ is the recommended minimum for safe driving) after selected time intervals (Table 2). ${ }^{35}$

CGM systems measure interstitial glucose and measurements obtained by CGM are currently not accepted by the DVLA as evidence of safe driving practice. The regulation states that 'blood' glucose measurements should be undertaken and not the interstitial tissue glucose concentration that is provided by CGM or flash glucose monitoring. Additionally, there is a significant lag time between the actual blood glucose and the interstitial glucose measurement, and reservations remain about accuracy, particularly at low glucose concentrations. With increasing adoption of CGM systems, many people with diabetes are questioning why glucose readings obtained by these devices cannot be used to demonstrate safe driving practice. Two studies have shown how these might be useful to detect hypoglycaemia occurring while driving, particularly asymptomatic episodes. 35,36 Continuous and often automatic monitoring of glucose levels would provide information to drivers which would alert them to potentially dangerous downward trends. Perhaps with the technological advances that are progressing apace with CGM and flash glucose monitoring, glucose sensors could be integrated within the display panel of a vehicle to alert the driver to a progressive fall in glucose.

\section{Conclusions}

The UK is one of the European countries with the strictest standards and regulations for drivers with diabetes; however, this does not mean that we should be complacent. While the UK has adopted and implemented all the EU driving regulations, the most recent changes will be, in our opinion, of debatable benefit to the promotion of road safety. The changes may represent a reaction of the EU regulators to the realisation that the previous version of the driving regulations has provoked deliberate concealment of severe hypoglycaemia by drivers with insulin-treated diabetes, negating efforts to identify those at greatest risk of driving accidents. It seems unlikely that these new amendments to the driving regulations will have a significant impact on the deceptively low rates of severe hypoglycaemia that are now being declared by individual drivers throughout Europe, which remains a very large hole in the current regulations through which anyone without scruples can steer with impunity.

How the regulations for drivers with diabetes can be altered to 


\section{Key messages}

- Hypoglycaemia can cause cognitive impairment that can impair driving performance; diabetic complications are a less common problem

- The estimated effect of diabetes on overall accident risk is modest

- The prospect of identifying drivers with diabetes who are at high risk of a road traffic accident is increasing

- European Union regulations on diabetes and driving have evolved to harmonise the differing regulations and practice that existed previously between countries

- The latest EU directive (implemented in the UK from January 2018) has advocated relaxation of some licensing regulations for drivers of Group 1 vehicles, but it is debatable whether these changes will benefit driving safety

promote safer driving practices is a more difficult question to answer. Specifying the time when a person's driving licence must be removed after two episodes of severe hypoglycaemia has not been effective and has only encouraged concealment by those affected, particularly where employment may be jeopardised. Reducing the period of proscription from 12 to 3 months is unlikely to alter attitudes or behaviour. A different regulatory approach to dealing with drivers experiencing recurrent severe hypoglycaemia is required, and they need to be encouraged to seek specialist assistance after a single episode of severe hypoglycaemia without any threat of immediate suspension of their driving licence. Narrowing the interval between blood glucose tests while driving may have an impact on reducing the risk of hypoglycaemia, but this cannot be enforced. Further research into the effects of hypoglycaemia (including episodes occurring during sleep) on driving performance and how hypoglycaemia can be avoided while driving is greatly needed, as hypoglycaemia as a cause of RTAs should be preventable.

\section{Conflict of interest None Funding None}

\section{References}

1. Graveling AJ, Frier BM. Driving and diabetes: problems, licensing restrictions and recommendations for safe driving. Clin Diabetes Endocrino/ 2015;1:8. https://doi.org/10.1186/s40842-015-0007-3

2. Graveling AJ, Warren RE, Frier BM. Hypoglycaemia and driving in people with insulin-treated diabetes: adherence to recommendations for avoidance. Diabet Med 2004;21:1014-19. http://dx.doi.org/10.1111/j.1464-5491.2004.01288.x

3. Inkster B, Frier BM. Diabetes and driving. Diabetes Obes Metab 2013; 15:775-83. http://dx.doi.org/10.1111/dom.12071

4. Hostiuc S, Negoi I, Hostiuc M. Diabetes and collision risk. A meta-analysis and meta-regression. Int J Clin Pract 2016;70:554-68. http://dx.doi.org/10.1111/ijcp.12832.
5. Cox DJ, Gonder-Frederick LA, Singh $\mathrm{H}$, et al. Predicting and reducing driving mishaps among drivers with type 1 diabetes. Diabetes Care 2017;40:74250. http://dx.doi.org/10.2337/dc16-0995

6. American Diabetes Association. Diabetes and driving. Diabetes Care 2014;37(Suppl 1):S97-103. https://doi.org/10.2337/dc14-S097

7. DVLA. Assessing fitness to drive: guide for medical professionals. Swansea: Department for Transport, 2016.

8. Houlden RL, Berard L, Cheng A, et al. Diabetes and driving: 2015 Canadian Diabetes Association updated recommendations for private and commercial drivers. Can J Diabetes 2015;39:347-53. http://doi.org/10.1016/j.jcjd.2015.08.011

9. Beshyah SA, Beshyah AS, Yaghi S, Beshyah WS, Frier BM. A global survey of licensing restrictions for drivers with diabetes. $\mathrm{Br} J$ Diabetes 2017;17 3-10. http://dx.doi.org/10.15277/bjd.2017.117

10. Hassoun AAK, Abdella N, Al Arouj M, et al. Driving and diabetes mellitus in the Gulf Cooperation Council countries: call for action. Diabetes Res Clin Pract 2015;110:91-4. http://dx.doi.org/10.1016/j.diabres.2015.08.002

11. World Health Organization. Global status report on road safety. Geneva: World Health Organization, 2015.

12. Pedersen-Bjergaard $U$, Faerch $L$, Allingbjerg ML, Agesen R, Thorsteinsson B. The influence of new European Union driver's license legislation on reporting of severe hypoglycemia by patients with type 1 diabetes. Diabetes Care 2015;38:29-33. http://dx.doi.org/10.2337/dc14-1417

13. Domgaard M, Bagger M, Rhee NA, Burton CM, Thorsteinsson B. Individual and societal consequences of hypoglycemia: a cross-sectional survey. Postgrad Med 2015;127:438-45. http://dx.doi.org/10.1080/00325481.2015.1045815

14. Broz J, Brabec M, Zdarska D, et al. Fear of driving license withdrawal in patients with insulin-treated diabetes mellitus negatively influences their decision to report severe hypoglycemic events to physicians. Patient Preferences and Adherence 2015;9:1367-70. https://doi.org/10.2147/PPA.587393

15. Rees $\mathrm{S}$, Browne A, Major H, Frier B. Renewal of driving licences and long duration insulin-treated diabetes: a comparison of medical assessment and self-reporting by drivers. Pract Diabetes 2012;29:117-19. http://dx.doi.org/10.1002/pdi.1671

16. European Commission. Commission Directive (EU) 2016/1106 amending Directive 2006/126/EC of the European Parliament and of the Council on driving licences. Off J Eur Union 2016;L183:59-63.

17. Geddes J, Wright RJ, Zammitt NN, Deary IJ, Frier BM. An evaluation of methods of assessing impaired awareness of hypoglycemia in type 1 diabetes. Diabetes Care 2007;30:1868-70. http://dx.doi.org/10.2337/dc06-2556

18. American Diabetes Association. Diabetes and driving. Diabetes Care 2012;35(Suppl 1):S81-6. http://dx.doi.org/10.2337/dc12-s081

19. Gubitosi-Klug RA, Braffett $\mathrm{BH}$, White NH, et al. Risk of severe hypoglycemia in type 1 diabetes over 30 years of follow-up in the DCCT/EDIC study. Diabetes Care 2017;40:1010-16. http://dx.doi.org/10.2337/dc16-2723

20. Cox DJ, Ford D, Gonder-Frederick L, et al. Driving mishaps among individuals with type 1 diabetes: a prospective study. Diabetes Care 2009; 32:2177-80. http://dx.doi.org/10.2337/dc08-1510

21. Redelmeier DA, Kenshole AB, Ray JG. Motor vehicle crashes in diabetic patients with tight glycemic control: a population-based case control analysis PLoS Med 2009;6(12):e1000192. http://dx.doi.org/10.1371/journal.pmed.1000192

22. Donnelly LA, Morris AD, Frier BM, et al. Frequency and predictors of hypoglycaemia in type 1 and insulin-treated type 2 diabetes: a population-based study. Diabet Med 2005;22:749-55.

http://dx.doi.org/10.1111/j.1464-5491.2005.01501.x

23. General Medical Council. Confidentiality: patients' fitness to drive and reporting concerns to the DVLA or DVA. 2017.

24. DCCT. Epidemiology of severe hypoglycemia in the diabetes control and complications trial. The DCCT Research Group. Am J Med 1991;90:4509. https://doi.org/10.1016/0002-9343(91)80085-Z

25. Graveling AJ, Frier BM. The risks of nocturnal hypoglycaemia in insulintreated diabetes. Diabetes Res Clin Pract 2017;133:30-9. http://dx.doi.org/10.1016/j.diabres.2017.08.012

26. King $\mathrm{P}$, Kong MF, Parkin $\mathrm{H}$, Macdonald IA, Tattersall RB. Well-being, cerebral function, and physical fatigue after nocturnal hypoglycemia in IDDM. Diabetes Care 1998;21:341-5. https://doi.org/10.2337/diacare.21.3.341

27. Jauch-Chara K, Hallschmid M, Gais S, et al. Hypoglycemia during sleep im- 
pairs consolidation of declarative memory in type 1 diabetic and healthy humans. Diabetes Care 2007;30:2040-5.

http://dx.doi.org/10.2337/dc07-0067

28. Brod M, Pohlman B, Wolden M, Christensen T. Non-severe nocturnal hypoglycemic events: experience and impacts on patient functioning and well-being. Qual Life Res 2013;22:997-1004. http://dx.doi.org/10.1007/s11136-012-0234-3

29. Brod M, Christensen T, Bushnell DM. Impact of nocturnal hypoglycemic events on diabetes management, sleep quality, and next-day function: results from a four-country survey. J Med Econ 2012;15:77-86. http://dx.doi.org/10.3111/13696998.2011.624144

30. Geelhoed-Duijvestijn PH, Pedersen-Bjergaard U, Weitgasser R, Lahtela J, Jensen MM, Ostenson CG. Effects of patient-reported non-severe hypoglycemia on healthcare resource use, work-time loss, and wellbeing in insulin-treated patients with diabetes in seven European countries. J Med Econ 2013;16:1453-61. http://dx.doi.org/10.3111/13696998.2013.852098

31. Frier BM, Jensen MM, Chubb BD. Hypoglycaemia in adults with insulintreated diabetes in the UK: self-reported frequency and effects. Diabet Med
2016;33:1125-32. http://dx.doi.org/10.1111/dme.12878

32. Feher MD, Langerman $H$, Evans M. Hypoglycemia, diabetes therapies and driving categories in type 2 diabetes. Curr Med Res Opin 2016;32:100512. http://dx.doi.org/10.1185/03007995.2016.1155981

32. Min T, Younis N. Driving and insulin-treated diabetes: are we aware of changes in the Third European Driving Licence Directive? Diabet Med 2016;33:553-4. http://dx.doi.org/10.1111/dme.12888

34. Watson WA, Currie T, Lemon JS, Gold AE. Driving and insulin-treated diabetes: who knows the rules and recommendations? Pract Diabetes 2007;24:201-6. http:dx.doi.org/10.1002/pdi.1097

35. Rayman G, Kroger J, Bolinder J. Could FreeStyle Libre sensor glucose data support decisions for safe driving? Diabet Med 2017 [Epub ahead of print 25 Sept 2017]. http://dx.doi.org/10.1111/dme.13515

36. Broz J, Donicova V, Brabec M, Janickova Zdarska D, Polak J. Could continuous glucose monitoring facilitate identifying diabetes patients with a higher risk of hypoglycemia during driving? J Diabetes Sci Technol 2013;7:1644-5. http://dx.doi.org/10.1177/193229681300700625 